thick and velvety walls. The remainder of the pericardium showed considerable thickening, with complete firm adhesion between its layers. The wall of the left ventricle was hypertrophied and the myocardium generally was of good colour and consistence. The mitral orifice admitted the tips of two fingers only and the tricuspid orifice was somewhat dilated, but there was no structural valvular disease. The base of

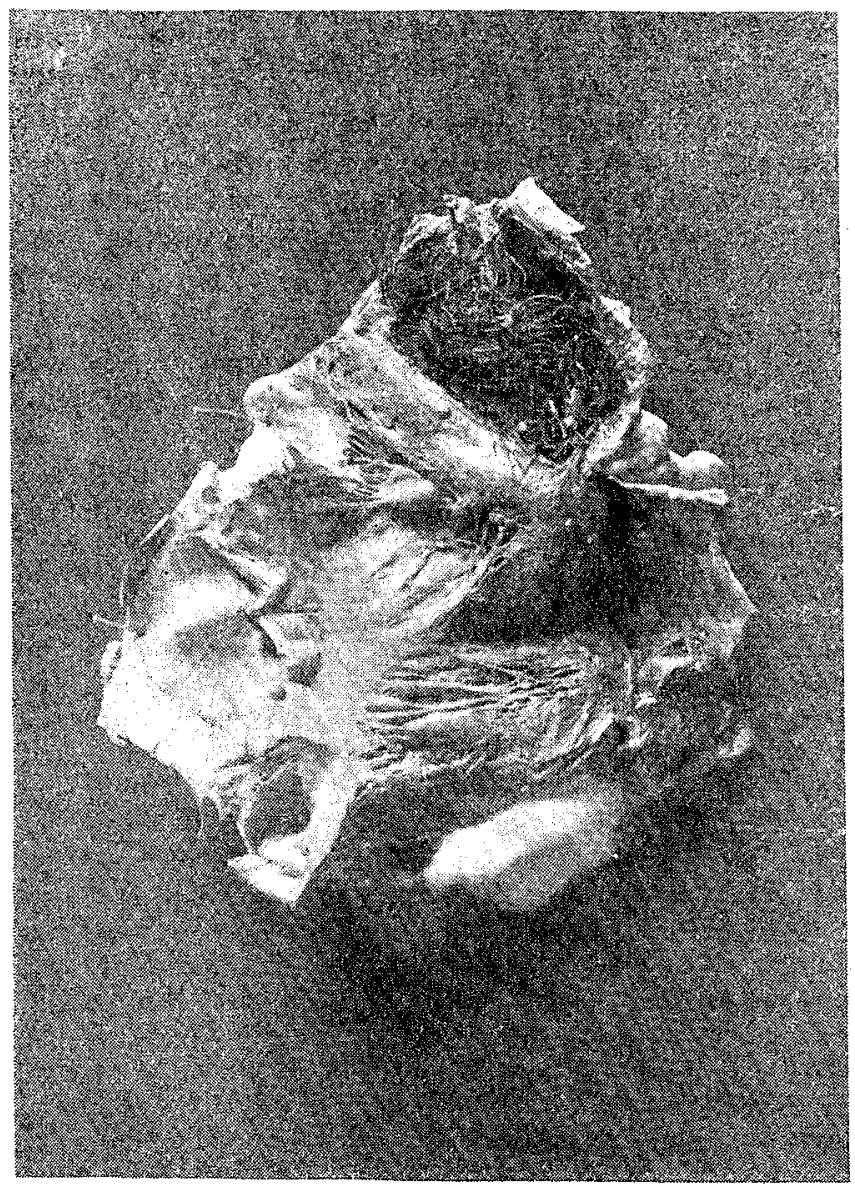

The illustration shows the interior of the left ventricle. The abscess in the pericardium contained horsehair on one side and cotton-wool on the other. Note the thickening of the visceral pericardium.

the aorta showed one or two small atheromatous patches. After dissection the heart and pericardium weighed 420 grammes. There were a few ounces of thin watery fluid in each pleura and some old firm adhesions. The right lung weighed 750 grammes and the left lung 540 grammes. They were very cedematous and had some hypostatic consolidation at the bases. The liver weighed 1360 grammes. It was congested and friable; the capsule was abnormally adherent, and on stripping left a coarsely granular surface. The spleen (which weighed 160 grammes) was somewhat enlarged and tough in consistence. The right kidney weighed 120 grammes and the left 150 grammes. The capsule in each was thickened and adherent, and in the cortex of each were many thin-walled cysts of various sizes. The cortex itself showed atrophy. The peritoneum contained a few ounces of clear watery fluid.

Remarks. - In this case the pericardial adhesion was eridently of old standing, as proved by its dense, firm, and inseparable nature. Probably the starting-point of the condition was an attack of acute or subacute pericarditis, as, according to Dr. F. T. Roberts, ${ }^{1}$ this is the cause in the large majority of such cases. The only record of such an illness is in January, 1892, that is, nearly eight years before the patient's death. That the existence of pericarditis was not then discovered is not alitogether surprising if one considers the demented condition of the patient and also that influenza was prevalent at the time. This supposition is supported by the fact that after this attack the patient never enjoyed good health. In all probability a chronic sero-fibrinous effasion became converted into a general purulent accumulation at a later date, a change possibly caused by the carbuncle which he suffered from in the following year or by the co-existing Bright's disease. Gradual absorption would

1 A System of Medicine, Professor T. Clifford Allbutt, 1893, vol. v., p. 780 . tben take place with the formation of the dense, firm adhesions, leaving the encapsuled collection of pus over the left ventricle, a situation to be expected on account of its wide range of movement.

I am indebted to Dr. J. T. Callcott, the medical superintendent, for permission to record this case.

Newcastle-on-Tyne.

\section{SOME CASES SHOWING THE USE OF "GAS AND OXYGEN" AS AN AN ESTHETIC IN CERTAIN OPHTHALMIC OPERATIONS}

By W. J. McCARDIE, B.A., M.B., B.C. CANTAB., ANASTHETIST TO THE GENERAL HOSPITAL, AND TO THE DENTAI HOSPITAL, BIRMINGHAM.

IN some ophthalmic operations a general anæsthetic is needful, ether or chloroform being the more commonly used. As many of these operations are but short ones the use of gas and oxygen whenever possible will obviously have great advantages over the other two anæsthetics. During the last two years I have administered the mixture in the 11 cases noted below in order of time. They were not specially selected by myself as suitable ones for "gas and oxygen," but I was asked to give the mixture and did so successfully in most of them. Hewitt's apparatus was used.

CASE 1. Removal of a small suppurating tumour of the eyebrow (with Dr. Wood White on March 26th, 1898).-The patient was a young man, very nervous, and rather unhealthylooking. Operation was performed in the consulting-room. The patient had a very light breakfast four and a half hours before. He took about two minutes to get under. The indicator at first was at 2 , then gradually moved on to 8 , where it was kept. When under the pupils were rather dilated and the eyeballs were insensitive and fixed; he was breathing quietly-snoring; his colour was as before anæsthesia; at the end of the fourth minute air was admitted, thinking the operation over, and conjunctival reflex returned. Inhalation was resumed till the end of the operation, no inconvenience being caused to the operator. The pulse was regular, rather slow, and of good volume. The duration of the operative anæsthesia was a little over four minutes. Good recovery ensued, although the patient was rather dazed and incoherent of speech for a few minutes. The operator did not find the apparatus in his way.

CASE 2. Tenotomy for strabismus (with Dr. Wood White). The patient was a girl, aged 14 years, strong and healthy, who came from a town about 30 miles away. She took the mixture exceedingly well; she had a good colour throughout and was allowed a little air once. There was no eye congestion. Operative anæsthesia lasted about two minutes. The eyeball moved rather awkwardly once or twice, but the body was absolutely still. There were no after-effects. The patient caught the next train back in half an hour very comfortably.

CASE 3. Tenotomy for strabismus (with Dr. Wood White).--The patient was a girl, aged 16 years. Operation was performed in the consulting-room. There was perfect anresthesia with absolute stillness of the eye and absence of congestion. Operation lasted about one minute. There were no after-effects whatever.

CASE 4. Tenotomy of the internal rectus for strabismus (with Mr. Eales at the Eye Hospital, Birmingham).-The patient was a boy, aged nine years. He took the anæsthetic well but the operator found the facepiece rather in the way and had therefore to work more slowly than usual. Towards the end of the operation there occurred some respiratory obstruction, owing probably to the tongue falling back, and a very slight congestion resulted. Rapid recovery ensued.

CASE 5. Tenotomy for internal strabismus (by Mr. Eales at the Eye Hospital).-The patient was a delicate girl, aged about seven years. There was a little cough at first, but she was soon under. The facepiece was kept applied till the operation was almost finished. There was no congestion. After removal of the facepiece there was retching for about half a minute and the patient then vomited about half an ounce of fluid. Mr. Eales admitted that the mixture was much better than "gas" alone and proposed on future occasions to operate quickly after removal of the facepiece. 
OASE 6. Excision of the eye (at the Eye Hospital, Birmingham).-The patient was an old woman, aged between 65 and 70 years. She was very nervous and restless. She was edentulous. The head was in the mid-line, I could not get the facepiece to fit as air entered at the sides owing to absence of the teeth and absorption of the jaws. I could not get her under so gave chloroform, which the patient took well. After removal of the eyeball a communication of the orbital with the cranial cavity, was found and I bad to administer chloroform for about 15 minutes. Gas and oxygen would have been rather difficult to administer for so long for such an awkward eye operation, and as matters turned out there would have been no special advantage in using the mixture, but rather the reverse.

CASE 7. Operation for entropion (with Dr. Wood White). The patient was a woman, aged between 65 and 70 years, in good health. Her head was a little raised on three pillows. She took the mixture quietly. Good anæsthesia. The indicator was kept at 8 or 10 . The head being in the mid-position the patient began to snore and presently got a little blue owing to respiratory obstruction, causing some venous oozing in spite of plenty of oxygen, so I removed the facepiece and by manipulation restored a free air-way and then re-applied the facepiece, and anæsthesia was continued without recovery. Towards the end a little phonation was heard, but it disappeared on putting back the indicator to 6. The operator stood behind the patient's head. Recovery was rapid and the patient complained of no after-effects at all. Operative anæsthesia lasted four minutes.

CASE 8. Tenotomy for strabismus (with Dr. Wood White).-The patient was a woman, aged about 30 years. Operation was performed in the consulting-room. The patient was very nervous at first, laughing hysterically, but she gradually became quiet. There was good colour throughout; she was allowed two breaths of air. Excellent anæsthesia. Quiet, full recovery in from two to three minutes.

CASE 9. Excision of small tumour of the right upper eyelid (by Dr. Wood White).--The patient was a bealtby young man, aged about 23 years. Operation was performed in the consulting-room. He took the mixture well and quietly. Once or twice the patient very slightly raised the right forearm and hand, but not inconveniently. He was slightly cyanosed at one time because I did not give him enough oxygen. Operative anæsthesia was just five minutes. Quiet recovery with no after-effects.

CASE 10. Tenotomy of the right internal rectus for strabismus (with Mr. N. H. Turner and Mr. Priestley Smith).The patient was a girl, aged four years. The child was stout, healthy, cheerful, and tractable. She was shown the apparatus and bags beforehand and induced to try to blow into them for amusement; she was then put on the table. The child took the mixture admirably, only once lifting her arms. The head was in the horizontal mid-line position. I used the latest pattern of Hewitt's stopcock and beginning with the indicator at 2 I quickly moved it on to 8 and kept it mostly between 8 and 10 , but occasionally opened the extra 10 inlet. A little cocaine was dropped into the eye before the conjunctival reflex had disappeared and when the operation was begun the eyeball was fixed, perfectly insensitive, and the pupils were of moderate size. The colour of the patient was very good throughout. The operation lasted from one to one and a half minutes as nearly as I could judge and during it the pulse and respira. tion were perfectly even and good. Recovery was very rapid and perfect, the child beginning to talk of many things in about a minute after removal of the facepiece and there were no after-effects. The child was not even fretful. Mr. Priestley Smith afterwards remarked that there was less congestion of the eyeball than there would have been during chloroform narcosis. This was a most successful case, for there are generally difficulties in administering gas or gas and oxygen to small children.

OASE 11. Scleral puncture for recurrent glaucoma of the left eye (with Mr. Priestley Smith).- The patient was aman, aged 60 years. The right eye had been already removed. The patient was of medium height, muscular, strong, and bearded. He lay in bed sideways to the window, the head of necessity being in the mid-line. As to the depth of anæsthesia I had, of course, to depend on respiration and colour chiefly. After well wetting the beard the facepiece was applied and the mixture was administered. The patient went under quietly, but when deep anæsthesia was attained the tongue fell back, with consequent cyanosis, venous engorgement, especially in the eje, and respiratory embarrassment. However, the operation was begun, the apparatus was removed, and by well pulling forward the chin proper breathing quickly returned and the venous engorgement disappeared. The patient then began to phonate a little, so more of the mixture was given, but a lighter anæsthesia was maintained till the operation, which was only a very short one, was finished, no further trouble occurring. The whole period of anæsthesia lasted about one and a half minutes. Recovery was extremely rapid and the patient declared that he had felt nothing of the operation, which, however, caused severe after-pain, necessitating the injection of morphia. Had it been possible in this case to have kept the patient's head on one side the respiratory embarrassment probably would not have occurred. I generally find that in children the head can be easily maintained in the horizontal mid-line position without causing falling back of the tongue; but in adults, and especially in strong plethoric men of middle age, it is often otherwise, more particularly when nitrous oxide is being administered.

Remarks. - I have not yet had an opportunity of trying the mixture for iridectomy or uncomplicated excision of the eyeball. Probably a deep enough anæsthesia for most eye operations is attainable in properly selected cases. Dexterous management is of course necessary in using the rather complex apparatus and the more so as the facepiece and stopcock are so near to the region of operation. It will be observed that the age of the youngest patient was four years and that of the oldest between 65 and 70 years.

The special advantages of using gas and oxygen in eye work are: (1) the almost absolute safety of the mixture, which is the safest anxsthetic known; (2) the rapid induction of anæsthesia, the patient being under in less than two minutes; (3) the induction is without incident and the maintenance in the best cases is quite sleeplike, while fall recovery occurs in less than two minutes; (4) the absence of after effects, the patient being able to leave the room in a very few minutes; (5) the eyeball is fixed, the orbicularis muscle is relaxed, and congestion can be entirely avoided by the allowance of sufficient oxygen, while there is no retching, sickness, cough, straining, or unconscious after-movement causing increased intra-ocular vascular tension; (6) the upright chair or semi-recumbent position on a couch can be conveniently and safely assumed; and (7) this method of anæsthetisation is, for several of the above given reasons, admirably adapted for consulting.room work.

If there be any doubt as to the success of the administration it is perhaps well to have an ether inhaler, ready charged, to band. It is not advisable to give chloroform after the mixture. With regard to limitations in usage it is not judicious to give gas and oxygen to big, strong, or much bearded men, to alcoholics of either sex, or to very young children, especially for delicate operations. In Case 6 it was impossible to give it to an edentulous and restless old woman. In adults especially it is important to keep the patient's head turned to one side to prevent obstruction to respiration, and in some cases the jaw must continuously be pushed forward to keep a free air-way. There is the disadvantage to the mixture that in operations immediately followed by pain the patient awakes at once to the sense of it and it may be necessary to inject morphia. Nevertheless, even if this be so, the absence of such after effects as retching, vomiting, \&c., which so often follow the administration of ether and chloroform, will alone more than compensate for the rapid awakening to pain. Occasionally the operator may find the facepiece in his way, but after a little experience he will probably be but little, if at all, inconvenienced.

After all, the greatest good can be obtained from this or any other anæsthetic by giving it to the most suitable patients and not by administering it indiscriminately in any or every case. Personally, I have been, on the whole, very pleased with the success attained, especially in the operations for strabismus, and in that particular one on the little child, aged four years (Case 10). I think that these cases show that gas and oxygen may be often used with advantage in certain ophthalmic operations. It does not seem quite fair to the patient, if the operation be of short duration, as is very frequently the case, to subject him to the risks attending the induction and maintenance of anæsthesia by 
chloroform or ether and to the unpleasant after effects of these drugs if such a substitute as gas and oxygen can possibly be employed.

Birmingham.

\section{ON A FATTY TUMOUR OF THE ASCEND- ING COLON ; ENTERECTOMY ; RECOVERY.}

Br J. BLAND-SUTTON, F.R.C.S. ENG.,

ASSISTANT SURGFON TO THE MIDDLESEX HOSPITAL; SURGEON TO THH CHEISEA HOSPITAL FOR WOMEN.

I1 has long been known that lipomata occur in the submucous coat of the stomach, jejunum, ileum, and colon, and they have been reported as forming one kind of rectal polypus. I have always been disposed to regard them as pathological curiosities until the case which forms the subject of this record came under observation.

Mr. W. Gifford Nash of Bedford asked me to see a man, 44 years of age, on account of trouble connected with the large bowel on the right side. The patient had suffered certainly for seven years from indefinite disturbances of the intestines; eventually the seat of trouble was localised in the neighbourhood of the cæcum. A physician of repute regarded the condition to be chronic inflammation of the excum and Mr. Nash strongly inclined to the opinion that the mischief was due to old appendicitis.

In November, 1899, the patient had a violent abdominal seizure and threatened intestinal obstruction. The rectum was emptied by enemata and obvious resistance could be felt in the region between the cæcum and the umbilicus. The pain was subsequently definitely centred in that spot throughout the rest of the illness. From this time onward the patient became liable to attacks of colic and a sensation as though something was being forced into the cæcum and on manipulation the lump could be passed upwards towards the umbilicus. By careful attention to the bowels the frequency of the attacks was diminished, but the urgency with which the attacks of colic appeared made the patient anxious for his life. In January, 1900, he sought the advice of Dr. W. Cayley. There was no difficulty in recognising the presence of a definite fairly mobile lump in the neighbourhood of the cæcum. Of its nature we could not be certain, but the long history of the symptoms encouraged us to dismiss carcinoma. In January I performed cœliotomy and exposed the cxcam. Two inches below the ileo-crcal valve a lump could be felt in the colon. The abdominal cavity was isolated with sterilised dabs and an incision was made over the tumour. This was ovoid, one pole being embedded between the mucous and muscular coats the remaining two-thirds of the tumour, covered with mucous membrane, projected into the lumen of the ascending colon. On splitting its capsule I was astonished to find a large lipoma. After enucleating it the mucous coat was sutured with a continuous silk suture and the muscular and serous coverings were drawn over it with interrupted silk sutures. The line of sutures remained exactly under the abdominal incision and I deemed is prudent to retain it in relation with the wound by means of a thin narrow strip of gauze. The margins of the wound were secured in three layers and dressed with ganze and Gamgee tissue. Recovery was uneventful and the patient is in excellent health.

The tumour is a lobulated lipoma weighing two ounces. Although it burrowed between the mucous and muscular coats of the bowel I think that it probably arose in the subserous fatty layer, because when engaged in removing the tumour I noticed a deep dimple in the serous investment of the colon immediately over the attached pole of the tumour. Mr. Stabb operated upon a man for acute intussusception of the ileum due to a lipoma and he draws attention to an infundibular recess in the serous coat of the gut at the base of the tumour. ${ }^{1}$ The lipoma which forms the subject of my communication is preserved in the museum of the Royal College of Surgeons of England.

Queen Anne-street, W.

\section{A CASE OF INCOMPLETE DEVELOPMENT OF THE THIRD AND FOURTH RIBS.}

BY F. B. JEFFERISS, M.R.C.S. ENG., L.R.C.P. LOND.

As there are only a limited number of these cases published I take the opportunity of describing the following instance which occurred in a rather poorly nourished boy, aged 12 years.

On inspection the right side of the chest presented obvious flattening and a deficiency in muscular covering which gave it a very wasted appearance. There was no nipple on this side. On abducting the right arm the anterior axillary fold was represented by a well-marked fold of skin extending from the level of the fourth costal cartilage to half-way down the arm; there was no muscle whatever in this fold. The first and second ribs appeared to be quite normal but seemed rather close together. Between the lower margin of the second rib and the upper margin of the fifth there was an obvious deficiency in the bony chest wall which extended out as far as the mid-axillary line. This space was covered by normal skin and under this was seen



The illustration shows the want of symmetry owing to the incomplete development of the third and fourth right ribs.

and felt a firm yielding fascia-like structure which was made up of tense vertical bands. One especially strong band extending between the second and fifth ribs at their union with their cartilages was well seen on deep inspiration. The right free margin of the sternum was easily felt with the prominences for articulation with the third and fourth costal cartilages. In the mid-axillary line a hard ill-defined prominence was felt which seemed to be the free end of the third rib. Half an inch below this the fourth rib was felt to run downwards towards the fifth and became indistinct apparently above and behind it at the anterior axillary fold There was no trace of the pectoralis major on the right side while the pectoralis minor was represented by a small but very strong muscular slip extending between the coracoid process and the first rib, near its cartilage. The right deltoid was more developed than the left. The boy has complele use of his right arm notwithstanding this deficient muscular development, all the movements being perfect, including c 3 